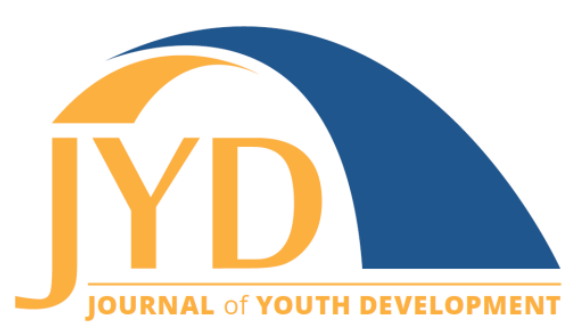

http://jyd.pitt.edu/ | Vol. 15 Issue 4 DOI 10.5195/jyd.2020.854 | ISSN 2325-4017 (online)

\title{
Book Review: The 5 Languages of Appreciation in the Workplace
}

\author{
Jamie Morris \\ University of Maryland Extension, 4-H Youth Development \\ jkenton@umd.edu
}

\begin{abstract}
The 5 Languages of Appreciation in the Workplace by Gary Chapman and Paul White (2012) is based on The 5 Love Languages by Chapman and research conducted by White into the relationships of co-workers and company environment. The book provides an understanding of the appreciation needs of others and offers practical actions that anyone can use in their workplace to demonstrate gratitude and potentially improve morale, connectedness, and engagement. The knowledge and suggestions provided in this book are transferable to volunteers, especially when they are an integral part of the workplace. In fact, incorporating appreciation into volunteer interactions recognizes their contributions, demonstrates their impact and may help to retain them as well.
\end{abstract}

Key words: appreciation, gratitude, recognition, motivation, workplace, volunteers

The need for appreciation is a human characteristic. Appreciation is the recognition of another's positive characteristics or contributions and can easily be demonstrated through the expression of genuine gratitude for an individual's impact on an organization, personal attribute, or quality. Although some may say they don't "do it" for the recognition, demonstrating appreciation in the workplace can improve relationships and productivity for all sizes and shapes of businesses, but it can truly be impactful for those whose workforce includes volunteers.

"Volunteers play an essential role in the delivery of educational programs conducted by the Cooperative Extension program in the United States" (Boyd, 2004, "Introduction," para. 1). These unpaid "employees" often provide essential work that may otherwise be left undone.

Their efforts may broaden program impacts by increasing an organization's reach and help fulfill

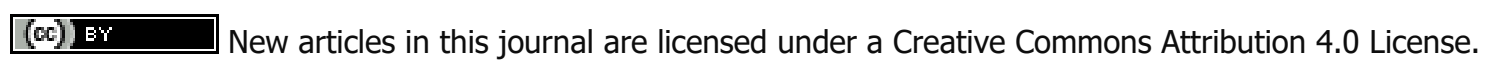
This journal is published by the University Library System, University of Pittsburgh and is cosponsored by the University of Pittsburgh Press. The Journal of Youth Development is the official peer-reviewed publication of the National Association of Extension 4-H Youth Development Professionals and the National AfterSchool Association. 
The 5 Languages of Appreciation in the Workplace

its mission and vision. When volunteers and their efforts are overlooked, negative feelings may arise, which is likely not the intention and certainly not to the benefit of an organization.

The 5 Languages of Appreciation in the Workplace by Gary Chapman and Paul White (2012) is designed to be used by any business or organization to infuse gratitude into the workday and improve productivity and office interactions. The information and strategies described in the book can also have quite an impact on organizations that rely heavily on volunteers. This book provides insight into the need for appreciation, but more importantly, the need to "speak" to others in their preferred language of appreciation to truly acknowledge their contributions. In The 5 Languages of Appreciation in the Workplace the authors lay a foundation that views appreciation as an investment and highlights how it can meet the needs of employees, including their need to feel connected, to have courage in their convictions, and to know that what they do really matters. "Without a sense of being valued by supervisors and colleagues, workers start to feel like a machine or a commodity" (Chapman \& White, 2012, p. 22). Many of the chapters, especially those highlighting the five languages, include workplace scenarios that can help the reader connect and see the benefit of incorporating appreciation into the workplace. A specific chapter is dedicated to each of the following languages, including simple and costeffective ways to use them:

- Words of Affirmation - The communication of praise of an individual delivered in person or in writing individually, to a group, or publicly.

- Quality Time - Intentionally spending time with an individual either in a work or leisure- related activity.

- Acts of Service - Assisting someone to complete a task when that assistance is not a part of your job requirement.

- Tangible Gifts - Giving an individual an item or object that is meaningful and may have monetary value.

- Physical Touch - Giving an individual a high five, handshake, or the proverbial "pat on the back."

Ultimately speaking to someone in their preferred language of appreciation can make them feel noticed and valued. Therefore, knowing the preferred languages for colleagues and volunteers would be beneficial, and there is a self-assessment that can help you find yours: the "Motivating by Appreciation" (MBA) Inventory. However, knowing someone's least preferred language may be more essential as that helps to identify an individual's "blind spot." This is the language that means the least to you, the one you will naturally use the least. By not using a specific 
language, it limits how appreciation is used or may be received which could inadvertently cause lessened connections or hurt feelings.

This book is an engaging and easy read. It provides useful information about how to use appreciation in the workplace and the benefits that can result from incorporating it into the daily business routine. It also provides helpful hints and best practices such as the need to be genuine in your appreciation. The knowledge and skills are useful in all types of businesses, but they may need modification to be used with volunteers.

Each book comes with a code to access the MBA Inventory. This is an online survey that asks an individual to select one of the two choices as their preferred method of appreciation in 30 paired work scenarios choices. The individual's answers are calculated based on the research of Chapman and White to identify their primary, secondary, and least preferred language of appreciation.

The MBA report includes an individual's preferences as well as details about how to demonstrate appreciation to the individual and "hit the mark" or why to avoid the least preferred language. It also includes

- an action checklist that one can share for others to understand how best to appreciate them,

- a summary that can be used to help incorporate authentic appreciation in one's workplace.

A number of resources and opportunities associated with The 5 Languages of Appreciation in the Workplace are available at https://www.appreciationatwork.com/5-languages-appreciationworkplace-improve-employee-engagement/, including

- Expanded MBA Inventory that can be used to compare individual results of a specific business or organization. There are different versions of this inventory designed for specific organizations such as the military or government.

- Training resources

- Training opportunities such as Appreciation at Work Certified Facilitator Course and The Vibrant Workplace Training Toolkit

If volunteers are essential to an organization, then volunteer appreciation should be essential as well. Appreciation can be classified as informal recognition-personalized gratitude to an individual for their contribution or support. "Such informal validations, which are always 
personal in nature, reinforce the vital concept that the most vibrant and resilient organizations are made up of individuals, coming together and sharing their unique strengths." (Lipp, 2011, p.3).

The 5 Languages of Appreciation in the Workplace provides a sound theoretical foundation for informal recognition efforts and the useful tool in the MBA Inventory, although the cost of the survey may be prohibitive for organizations with limited budgets. Some work may be needed to "translate" workplace suggestions to apply to volunteer relationships. Intentional efforts to incorporate these appreciation concepts into volunteer development may include providing a training that overviews the languages and provides suggestions and concrete examples of how to use the languages. Another simple adaptation would be to create a tip sheet of how to speak the language and how to help others speak the language with suggestions such as:

- Post a personal thank you to workshop presenters with a picture from the workshop on your Facebook page (how to speak the language of Words of Affirmation).

- Create a thank you graffiti wall for a workshop presenter (help others speak the language of Words of Affirmation).

Finding ways to incorporate The 5 Languages of Appreciation in the Workplace into your volunteer development plan may take a little thought and time. In the end it will be worth it when you see the benefit, whether that be a smile on a volunteer's face or an increase in your volunteer participation rate. "Effectively conveying your appreciation for the work they are doing in ways that are meaningful to the volunteer can significantly boost volunteer retention." (Chapman \& White, 2012, p.143). Try showing genuine appreciation in the form of a pat on the back, kind word, simple act of service, sharing some quality time or giving a small gift; see how it feels and wait for its impact.

\section{References}

Boyd, B. (2004). Extension agents as administrators of volunteers: Competencies needed for the future. Journal of Extension, 42(2), Article 2FEA4. https://www.joe.org/joe/2004april/a4.php

Chapman, G. D, \& White, P. E. (2012). The 5 languages of appreciation in the workplace: Empowering by encouraging people. Northfield.

Lipp, J. L. (2011). Informal volunteer recognition: Creating a culture of appreciation. http://www.everyoneready.info/sites/default/files/ER SIGuide SAMPLE.pdf 